\title{
Association between Genetic Polymorphism of Multidrug Resistance 1 Gene and Sasang Constitutions
}

\section{Hyun-Ju Kim ${ }^{1}$, Seung Yeon Hwang ${ }^{2}$, Ju-Ho Kim ${ }^{1}$, Hye-Jung Park', Sang-Gyu Lee ${ }^{2}$, Si-Woo Lee ${ }^{3}$, Jong-Cheon Joo $^{2}$ and Yun-Kyung Kim ${ }^{1}$}

${ }^{1}$ College of Pharmacy, ${ }^{2}$ College of Oriental Medicine, Wonkwang University, Jeonbuk and ${ }^{3}$ Korea Institute of Oriental Medicine, Daejeon, Republic of Korea

\begin{abstract}
Multidrug resistance $1(M D R l)$ is a gene that expresses P-glycoprotein (P-gp), a drug transporter protein. Genetic polymorphisms of $M D R 1$ can be associated with Sasang constitutions because Sasang constitutional medicine (SCM) prescribes different drugs according to different constitutions. A Questionnaire for Sasang Constitution Classification II (QSCC II) was used to diagnose Sasang constitutions. Two hundred and seven healthy people whose Sasang constitutions had been identified were tested. Genotype analyses, restriction fragment length polymorphism (RFLP) and pyrosequencing were used in MDR1 C1236T, and in MDR1 G2677T/A and C3435T, respectively. Significant differences in MDRl C1236T genotypes were found between So-yangin and So-eumin. MDRl G2677T/A genotype also showed significant differences in allele distribution between So-yangin and Tae-eumin. So-yangin and So-eumin showed significant differences in the distribution of both 1236C-2677G-3435C and 1236T-2677G-3435T, haplotypes of $M D R 1$. The genetic polymorphism of the MDRl gene was thus shown to be an indicator that could distinguish So-yangin from other constitutions.
\end{abstract}

Keywords: ABCB1 (MDR1) - P-glycoprotein - pyrosequencing - Sasang constitutional medicine

\section{Introduction}

In Sasang constitutional medicine (SCM), a unique traditional individualized medicinal system in Korea, human beings are classified into four constitutions. Diagnosis of Sasang constitutions utilize physical observational categories such as physical appearance and facial features as well as the way of speaking, mental characteristics such as temperament and talent and constant mind, symptomatic observation categories such as healthy state, disease-specific symptoms, major diseases, common symptoms, etc. (1).

For reprints and all correspondence: Yun-Kyung Kim, Assistant Professor, Department of Oriental Pharmacy, College of Pharmacy, Wonkwang University, 344-2 Shinyong-dong, Iksan, Jeonbuk, 570-749, Republic of Korea. Tel/Fax: +82-63-850-6803;

E-mail: hestia@wku.ac.kr
In addition, different drugs are applied according to the Sasang constitution of the individual, and sometimes constitution is diagnosed based on reaction to a specific drug. Differences in the process by which a drug works and produces its efficacy in the body is considered to determine the differences in sensitivity to the drug among the Sasang constitutions and may therefore play an important role in identifying the constitution.

For this reason, symptomatic observations are used in the form of inquiry or drug-based diagnosis, which evaluates the response after administration of herbal medication and is thought to be most crucial in diagnosis (2).

Recently, active research has been conducted on the association of genes and Sasang constitutions for constitution diagnosis using genetic information. This is based on common points between genes and Sasang constitutions such as inherence, lifelong permanence and 
determination of body shapes and functions (3). In a study with 163 subjects from 37 families, to prove that the Sasang constitution was inherited, the correlation between the parents' constitution and their children's constitution was examined through Fisher's exact test, kappa coefficient and correspondence analysis. It was reported that the parents' constitution, in particular the mother's constitution, was inherited by their children (4). Genes presumed to be associated with the Sasang constitution are angiotensin converting enzyme (ACE) (5), human leukocyte antigen $(H L A)(6)$, interleukin-1 receptor antagonist $(I L-1 R a)(7)$, interleukin-1 beta $(I L-1 \beta)(8)$, cholecystokinin $(C C K)$ (9), cytochrome P450 (CYP450) $(10,11)$, among others. It was reported that the $A C E$ gene Type II was associated with So-eumin and Type DD with Tae-eumin. In obese women, the $I L-1 \beta$ gene was associated with body mass index (BMI), and with Tae-eumin. It was also reported that in the $C C K$ gene, the $\mathrm{C} / \mathrm{T}$ type, one of the variations of promoter 1421, was significantly different among the Sasang constitution groups. Some studies have reported that cytochrome P450, a functional gene associated with the metabolism of various drugs, has different distribution patterns based on the Sasang constitution of the individual (11). The multiplex DNA amplification and detection of single nucleotide polymorphisms (SNPs) on microarrays are ideal for SNP or mutation detection analysis and can also be applied to Sasang diagnostics in the future (12).

The multidrug resistance 1 (MDR1) gene, which is involved in drug transportation, was first identified in 1976 by Juliano and Ling, who showed that P-gp was expressed as an MDR1 phenotype (13). P-gp plays a role in protecting the body by discharging toxic foreign substances and metabolic products through bile juice, urine or intestinal lumen and preventing them from accumulating in the brain, testicle or fetus $(14,15)$. The expression of P-gp in the gastrointestinal tract controls the absorption of drugs, and this restricts the transportation of the drug to its acting locus. Consequently the expression of P-gp has a direct effect on in vivo drug concentration (16). In addition, MDRl genetic polymorphism has a considerable effect on the expression and activity of P-gp (17).

It was reported that $M D R 1$ genetic polymorphism varies among races. The distribution of MDR1 genetic polymorphism in Asians is different from that of Caucasians or Africans; even among Asians, Koreans show a different distribution of this genetic polymorphism compared with Malaysians or Chinese (18). Thus, within Koreans, the distribution of polymorphism is likely to be different according to the characteristic of localities or the nature of groups. That is, the distribution may be different among the groups of Sasang constitution, which is an overall expression of mental and physical characteristics.

The possible reasons for variations in efficacy of drugs based on Sasang constitution are as follows. Genetic variations in drug metabolism may exist among patients. Thus, drug-metabolizing enzymes such as CYP450 may function differently in each constitution. Differences in genes regulating drug transporters such as MDRl may also be involved, as this would affect the transport of a metabolized drug to the acting locus. Variations in effects of the same drug due to polymorphism of target receptors or genes involved in signal transduction should also be considered (19).

The MDRl gene has around 100 SNPs. Here, we investigated the three major SNPs: C1236T is located in exon 12, G2677T/A in exon 21 and C3435T in exon 26 (Fig. 1). The present study examined the association of the main polymorphisms of C1236T located in exon 12,

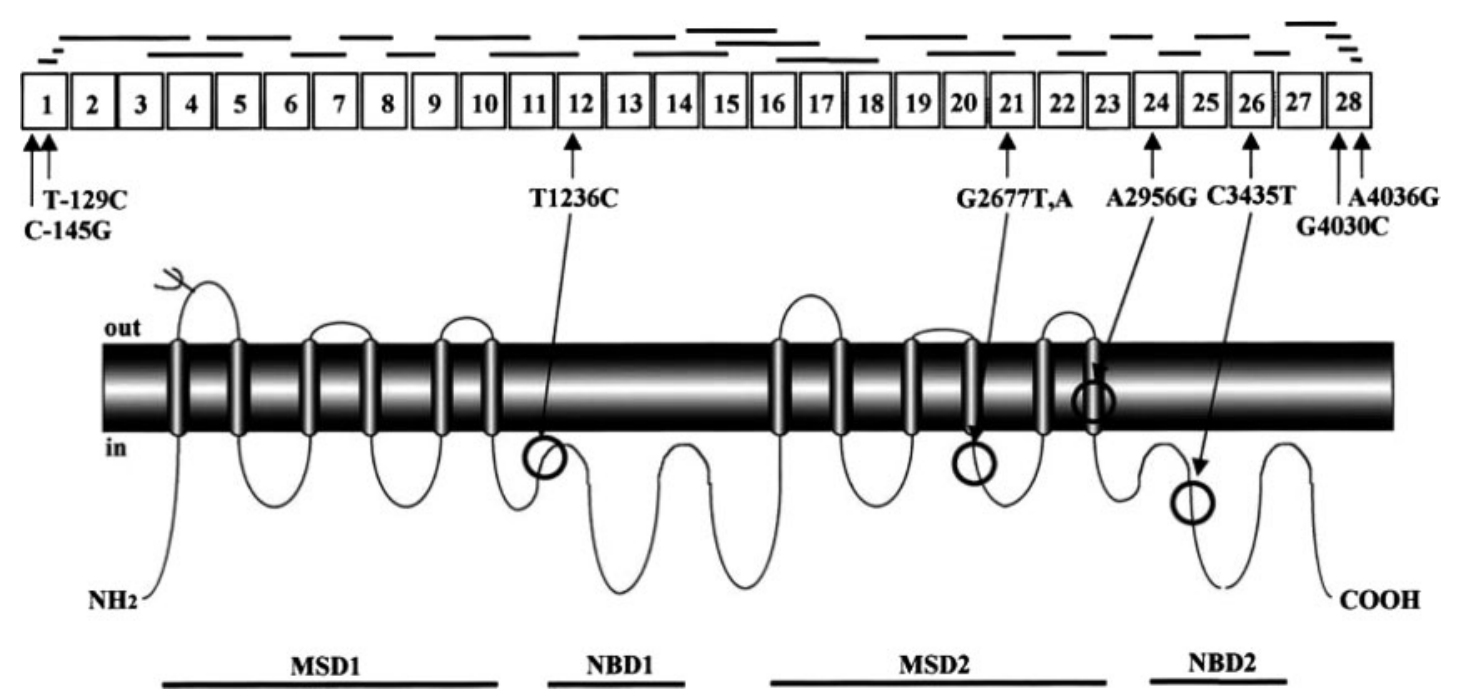

Figure 1. The locations of the identified polymorphisms (arrows) are indicated in relation to the exon structure of the human $M D R-1$ gene and the predicted topology of P-gp. 
G2677T/A in exon 21 and C3435T in exon 26 among some 100 SNPs of the MDRl gene with Sasang constitutions.

\section{Methods}

\section{Subjects and DNA Extraction}

This study was conducted with young and healthy volunteers from March 2004 to December 2006. The Institutional Review Boards of Wonkwang University Hospital approved the protocol of the present study. The subjects were confirmed to be $\geq 18$ years without any particular disease. Before participating in the test, the subjects were given information on the contents and procedure of the test, and voluntary written consent was obtained from each subject. Sasang constitution was diagnosed using the Questionnaire for Sasang Constitution Classification II (QSCC II), which was developed by Kyunghee University and programmed in 1996. Among 290 volunteers in our study, 207 individuals got the concrete Sasang constitution diagnosis with QSCC II. Three milliliters of blood was drawn by venipuncture and the DNA was extracted. The concentration and purity of isolated DNA were determined by the OD260/OD280 absorbance ratio.

\section{Polymerase Chain Reaction and Restriction Fragment Length Polymorphism Analysis of MDR1 C1236T}

The SNPs were detected by sequence-specific primer polymerase chain reaction (SSP-PCR) using primer mixes (Table 1). The PCR reaction was amplified using a PCR machine (TAKARA, Japan). Denaturation was conducted for $30 \mathrm{~s}$ at $94^{\circ} \mathrm{C}$, and then cycles of DNA denaturation at $94^{\circ} \mathrm{C}$ for $30 \mathrm{~s}$, primer annealing at $55^{\circ} \mathrm{C}$ for $1 \mathrm{~min}$, and extension at $72^{\circ} \mathrm{C}$ for $30 \mathrm{~s}$ were repeated 35 times. In the last cycle, DNA synthesis was conducted at $72^{\circ} \mathrm{C}$ for $10 \mathrm{~min}$ so that the $3^{\prime}$-end of the DNA under synthesis was filled completely. Electrophoresis of the

reactant in $2 \%$ agarose gel confirmed the presence of the amplicons obtained from the PCR.

Genotype analysis was conducted using restriction fragment length polymorphism (RFLP) for MDR1 C1236T. The PCR product was digested with Hae III restriction enzyme (New England BioLabs, Beverly, MA, USA) which digests only the wild-type allele in the mutation allele of MDR1 1236 (Fig. 2).

\section{Pyrosequencing of MDR1 G2677T/A and C3435T}

Pyrosequencing analysis was carried out using a PSQ 96 machine (Pyrosequencing Advanced Biotechnologies, Uppsala, Sweden) and sequencing primers of MDR1 2677 and 3435 were 5'-GATAAGAAAGAACTAGA AGG-3' and 5'-GGTGTCACAGGAAGAGAT-3', respectively.

After the immobilization of the PCR product using streptavidin sepharose beads (streptavidin sepharose HP, Amersham Pharmacia Biotech, Uppsala, Sweden), the sequencing primer was combined with single-stranded DNA by incubating the PSQ 96 Plate Low at $95^{\circ} \mathrm{C}$ for $2 \mathrm{~min}$, and then at room temperature for $5 \mathrm{~min}$. The PSQ 96 Plate Low and a cartridge filled with the substrate, enzyme and nucleotides of PSQ 96 SNP Reagent kit (Pyrosequencing Advanced Biotechnologies, Uppsala, Sweden) were put in the chamber of a PSQ 96 machine (Pyrosequencing Advanced Biotechnologies) and analysis was conducted.

Table 1. Primer sequences used in PCR amplification

\begin{tabular}{ll}
\hline Name & Sequence \\
\hline $\begin{array}{l}\text { MDR1 1236 } \\
\text { sense primer }\end{array}$ & $5^{\prime}$-TCTTTGTCACTTTATCCAGC-3' \\
$\begin{array}{l}\text { MDR1 1236 } \\
\text { anti-sense primer }\end{array}$ & $5^{\prime}$-TCTCACCATCCCCTCTGT-3' \\
MDR1 2677 & \\
sense primer & $5^{\prime}$-TGTTGTCTGGACAAGCACTGA-3' \\
MDR1 2677 & 5'-Bio-GCATAGTAAGCAGTAGGGA \\
anti-sense primer & GTAACAA-3' \\
MDR1 3435 & $5^{\prime}$-GGGTGGTGTCACAGGAAGAG-3' \\
Sense primer & \\
MDR1 3435 & $5^{\prime}$-Bio-CATGCTCCCAGGCTGTTTAT-3' \\
Anti-sense primer & \\
\hline
\end{tabular}
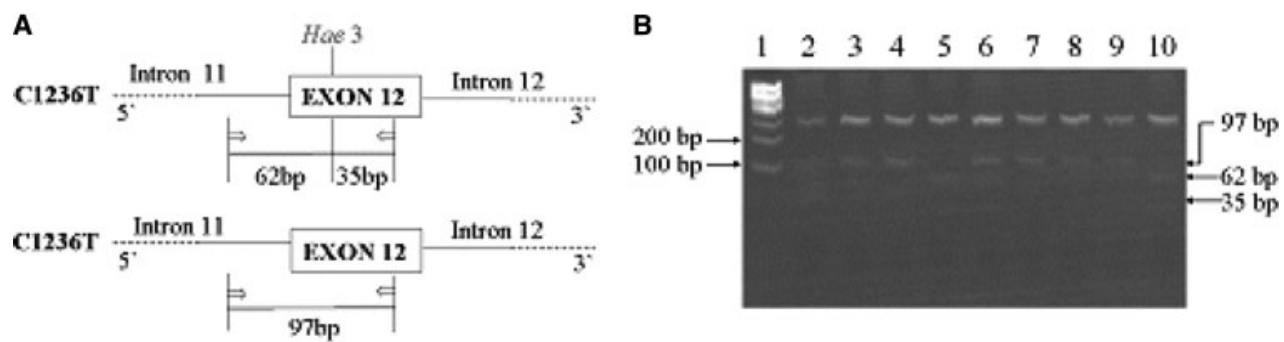

Figure 2. PCR-based diagnostic test for MDR1 C1236T mutation. (A) Strategy used to genotype genomic DNA from human blood, utilizing PCR amplification of exon 12 followed by Hae $\beta$ digestion. (B) Agarose gel electrophoresis shows the analysis of MDR1 C1236T. Note: Lane 1 is $100 \mathrm{bp}$ size marker. Lanes 5 and 10 are homozygous $(\mathrm{C} / \mathrm{C}$ type), lanes 4 and 7 are wild-type (T/T type), lanes 2, 3, 6, 8 and 9 are heterozygous $(\mathrm{C} / \mathrm{T}$ type). 

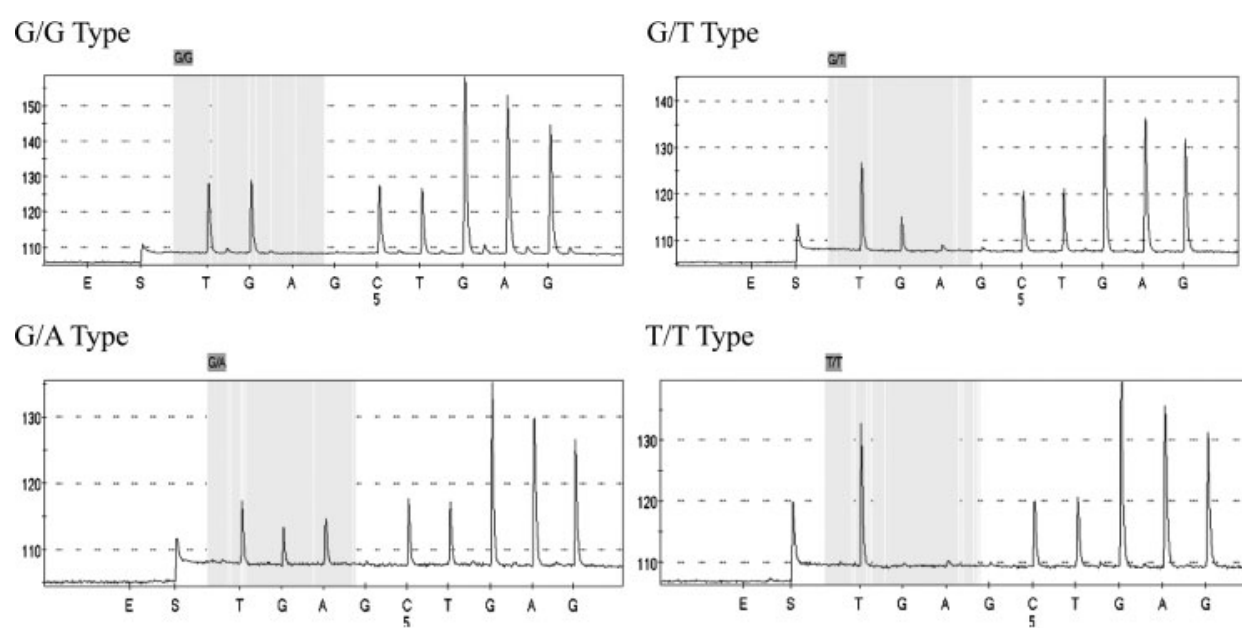

T/T Type

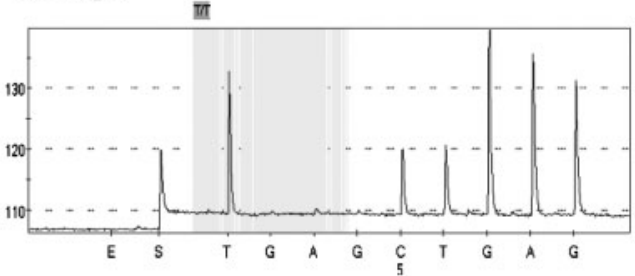

T/A Type

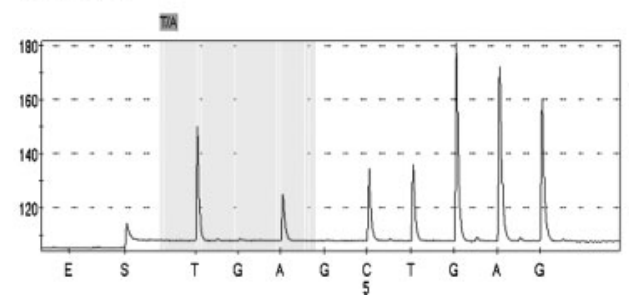

A/A Type

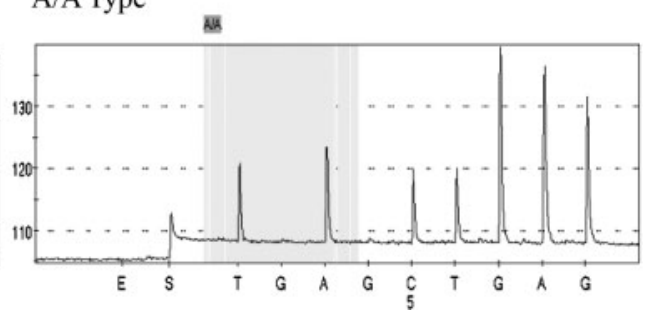

Figure 3. Representative pyrograms for the genotyping of the G2677T/A SNP illustrating a homozygous wild-type (G/G), a heterozygous G/T, a $\mathrm{T}$ homozygous individual (T/T), a G/A heterozygous individual, a T/A heterozygous and an A homozygous individual (A/A).
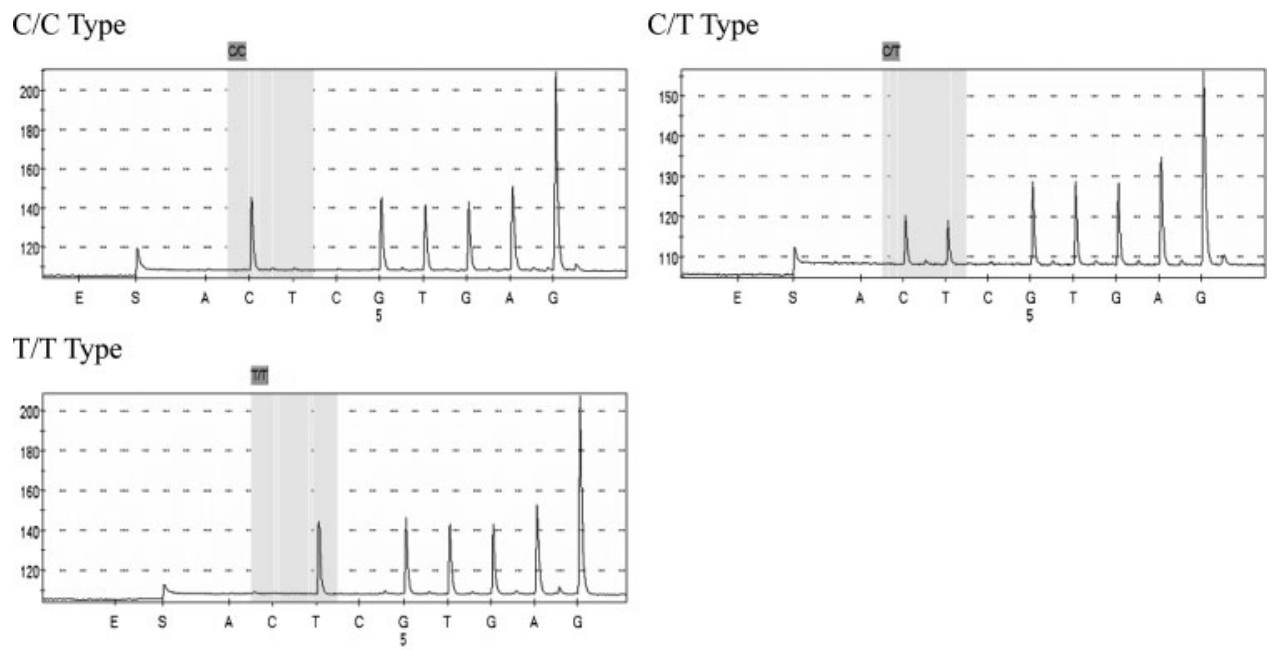

Figure 4. Representative pyrograms for the genotyping of the C3435T SNP illustrating an individual homozygous wild-type (C/C), a heterozygous $(\mathrm{C} / \mathrm{T})$ and a $\mathrm{T}$ homozygous individual $(\mathrm{T} / \mathrm{T})$.

Through the above-described process, we investigated the $\mathrm{G}>\mathrm{T} / \mathrm{A}$ polymorphism of position 2677 of the MDRl gene, and the $\mathrm{C} / \mathrm{T}$ polymorphism of position 3435 (Figs 3 and 4).

\section{Statistical Analysis}

Statistical analysis was performed using SPSS 12.0 (SPSS Inc., USA). Differences in genotype distribution among the Sasang constitution groups were analyzed using the chi-squared test. The significance level was 0.05 . The haplotype structure of the MDRl gene was determined using three different SNPs and analyzed using the SNPAlyze software (DYNACOM, Japan).

\section{Results}

\section{Proportions of each Sasang Constitution}

Of the 207 subjects, $51(24.7 \%)$ were Tae-eumin, 56 $(27.0 \%)$ were So-yangin and $100(48.3 \%)$ were So-eumin. 
The prevalence of the Tae-yangin is assumed to be very low in the literature $(3,20)$, therefore, no one was diagnosed as Tae-yangin. The average age was 25.4 years, and 130 subjects were males while 77 were females (Table 2).

\section{MDR1 C1236T Genotype and Allele Frequency}

The distribution of MDRI C1236T genetic polymorphism among the Sasang constitution groups is shown in the Table 3. When the Sasang constitution groups were compared two by two, significant differences were observed between the So-yangin group and the So-eumin group $(P=0.03)$ (Table 3$)$. However, there was no significant difference in the distribution of the MDRI C1236T gene allele frequency among the Sasang constitution groups.

\section{MDR1 G2677T/A, C3435T Genotype and Allele Frequency}

In the MDR1 G2677T/A region, no significant difference was observed among the Sasang constitution groups

Table 2. Distribution of Sasang constitutions

\begin{tabular}{llll}
\hline & Tae-eumin & So-yangin & So-eumin \\
\hline Total, $n(\%)$ & $51(24.7)$ & $56(27.0)$ & $100(48.3)$ \\
Age (years) & $26.3 \pm 5.0$ & $25.2 \pm 5.6$ & $24.6 \pm 4.4$ \\
Gender $(\%)$ & & & \\
$\quad$ Males & $38(74.5)$ & $30(53.6)$ & $62(62.0)$ \\
Females & $13(25.5)$ & $26(46.4)$ & $38(38.0)$ \\
\hline
\end{tabular}

Table 3. Frequencies of MDR1 C1236T genotype and Sasang constitutions

\begin{tabular}{lllll}
\hline & $\begin{array}{l}\text { Tae-eumin } \\
(n=51)(\%)\end{array}$ & $\begin{array}{l}\text { So-yangin } \\
(n=56)(\%)\end{array}$ & $\begin{array}{l}\text { So-eumin } \\
(n=100)(\%)\end{array}$ & $P^{*}$ \\
\hline $\mathrm{T} / \mathrm{T}$ & $17(33.3)$ & $23(41.1)$ & $25(25.0)$ & \\
$\mathrm{C} / \mathrm{T}$ & $28(54.9)$ & $23(41.1)$ & $62(62.0)$ & $0.33^{\mathrm{a}} / 0.03^{\mathrm{b}} / 0.55^{\mathrm{c}}$ \\
$\mathrm{C} / \mathrm{C}$ & $6(11.8)$ & $10(17.9)$ & $13(13.0)$ & \\
\hline
\end{tabular}

${ }^{\mathrm{a}}$ Tae-eumin versus So-yangin; ${ }^{\mathrm{b}} \mathrm{So}-$ yangin versus So-eumin; ${ }^{\mathrm{c}}$ Tae-eumin versus So-eumin; *Values calculated by $\chi^{2}$-test. (data not shown). However, in the distributional analysis of the MDR1 G2677T/A gene allele among the Sasang constitution groups, significant differences were observed by $\chi^{2}$ test between the Tae-eumin group and the So-yangin group $(P=0.04)$ (Table 4$)$. The genotype and allele frequency of the C3435T region among the Sasang constitution groups showed no significant difference.

\section{Distribution of MDR1 C1236T, G2677T/A and C3435T Haplotypes}

In the MDRlgene, C1236T, G2677T/A and C3435T haplotypes among the Sasang constitution groups showed some variation. The distribution of MDRl genotypes in 207 samples was compared with HardyWeinberg equilibrium by $\chi^{2}$ test to check for selection bias. There was a significant difference between the So-yangin group and the So-eumin group in C-G-C, one of major haplotypes $(P=0.04)$, and between the So-yangin group and the So-eumin group in haplotype T-G-T $(P=0.03)$. In minor haplotypes T-A-C and C-T-T as well, significant differences were observed among the Sasang constitution groups (Table 5).

\section{Discussion}

The purpose of this study was to find scientific evidence that there are differences between the Sasang constitutions. To diagnose the Sasang constitution of the volunteers, we used the objective questionnaire, QSCC $\alpha$.

Table 4. Frequencies of MDR1 G2677T/A allele in Sasang constitutions

\begin{tabular}{lllll}
\hline & $\begin{array}{l}\text { Tae-eumin } \\
(n=102)(\%)\end{array}$ & $\begin{array}{l}\text { So-yangin } \\
(n=112)(\%)\end{array}$ & $\begin{array}{l}\text { So-eumin } \\
(n=200)(\%)\end{array}$ & $P^{*}$ \\
\hline $\mathrm{G}$ & $54(52.9)$ & $40(35.7)$ & $89(44.5)$ & $0.04^{\mathrm{a}} / 0.31^{\mathrm{b}} / 0.37^{\mathrm{c}}$ \\
$\mathrm{T}$ & $32(31.4)$ & $47(42.0)$ & $73(36.5)$ & \\
$\mathrm{A}$ & $16(15.7)$ & $25(22.3)$ & $38(19.0)$ & \\
\hline
\end{tabular}

${ }^{\mathrm{a}}$ Tae-eumin versus So-yangin; ${ }^{\mathrm{b}}$ So-yangin versus So-eumin; ${ }^{\mathrm{c}}$ Tae-eumin versus So-eumin; *Values calculated by $\chi^{2}$-test.

Table 5. Haplotype frequencies of MDR1 SNPs in Sasang constitutions

\begin{tabular}{|c|c|c|c|c|c|c|}
\hline \multicolumn{3}{|c|}{ Haplotypes of MDR1 gene } & \multicolumn{3}{|c|}{ Haplotype frequency in each group } & \multirow{2}{*}{$\begin{array}{l}P^{*} \\
P^{\mathrm{a}} / P^{\mathrm{b}} / P^{\mathrm{c}}\end{array}$} \\
\hline $\mathrm{T} 1236 \mathrm{C}$ & G2677T/A & $\mathrm{C} 3435 \mathrm{~T}$ & $\begin{array}{l}\text { Tae-eumin } \\
(n=51)(\%)\end{array}$ & $\begin{array}{l}\text { So-yangin } \\
(n=56)(\%)\end{array}$ & $\begin{array}{l}\text { So-eumin } \\
(n=100)(\%)\end{array}$ & \\
\hline $\mathrm{T}$ & $\mathrm{T}$ & $\mathrm{T}$ & 24.08 & 26.47 & 28.58 & $0.68 / 0.68 / 0.40$ \\
\hline $\mathrm{T}$ & G & $\mathrm{C}$ & 24.22 & 15.83 & 17.14 & $0.12 / 0.76 / 0.14$ \\
\hline $\mathrm{C}$ & A & $\mathrm{C}$ & 13.44 & 14.46 & 14.98 & $0.82 / 0.90 / 0.71$ \\
\hline $\mathrm{T}$ & $\mathrm{T}$ & $\mathrm{C}$ & 5.24 & 5.26 & 4.53 & $0.99 / 0.77 / 0.78$ \\
\hline $\mathrm{C}$ & $\mathrm{T}$ & $\mathrm{T}$ & - & 4.85 & - & $0.02 / 0.001 /-$ \\
\hline $\mathrm{T}$ & $\mathrm{A}$ & $\mathrm{T}$ & - & - & 2.74 & $-/ 0.07 / 0.32$ \\
\hline $\mathrm{C}$ & G & $\mathrm{T}$ & 1.29 & - & 2.45 & $0.22 / 0.09 / 0.50$ \\
\hline
\end{tabular}

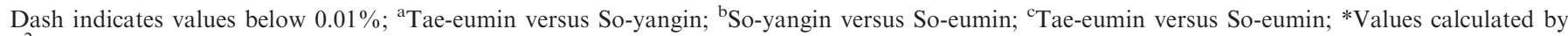
$\chi^{2}$-test. 
The accuracy of the results of QSCC $\alpha$, compared with the diagnosis of the SCM specialists, was $70.08 \%$ (21). Although there are some questions regarding the low discrimination accuracy, it is the most standardized and widely used tool for SCM diagnosis until now (22).

Because we thought the most crucial part of the differences can be the drug response, we targeted MDRl, the drug transporter. We investigated the SNPs and haplotypes of the MDRl gene, and examined their association with the Sasang constitutions. There was a report that the first factor determining the expression and activity of P-gp was not SNPs but the haplotype of MDRI (17). A haplotype is a set of SNPs, and is inherited in each chromosome. As large-scale experiments became feasible, researchers are introducing the concept of haplotype as a group obtained by analyzing multiple SNPs from many experiments $(23,24)$. Among the SNPs of the MDRl gene, this study was conducted on C3435T, G2677T/A and C1236T, which cause important variations in the activity of P-gp and show high frequency among Koreans (25).

It was reported that, for C1236T genetic polymorphism, the $\mathrm{C} / \mathrm{C}$ type was more frequent than the $\mathrm{T} / \mathrm{T}$ type in Caucasians, whereas the $\mathrm{T} / \mathrm{T}$ type was more frequent than $\mathrm{C} / \mathrm{C}$ type in Asians $(18,26)$. Among the Asian population, the $\mathrm{T} / \mathrm{T}$ type was shown to be more frequent than the $\mathrm{C} / \mathrm{C}$ type in Koreans, but then the Koreans showed a relatively higher frequency of the $\mathrm{C} / \mathrm{T}$ type than the Chinese and Japanese $(26,27)$. The results of the present study were similar to other studies on the general distribution of Sasang constitutions in Koreans.

According to the distribution pattern of the C1236T gene among the Sasang constitutions, the percentage of homozygous $\mathrm{C} / \mathrm{C}$ type or $\mathrm{T} / \mathrm{T}$ type was low and that of heterozygous $\mathrm{C} / \mathrm{T}$ type was high in Tae-eumin and Soeumin. In So-yangin, however, the percentage of $\mathrm{C} / \mathrm{C}$ type or $\mathrm{T} / \mathrm{T}$ type was high and that of $\mathrm{C} / \mathrm{T}$ type was low. In particular, So-eumin showed a far higher percentage of $\mathrm{C} / \mathrm{T}$ type than that of $\mathrm{C} / \mathrm{C}$ type or $\mathrm{T} / \mathrm{T}$ type, and was therefore significantly different from So-yangin, which showed a relatively low percentage of $\mathrm{C} / \mathrm{T}$ type. This indicated that an individual, whose MDRl C1236T genotype was $\mathrm{C} / \mathrm{T}$, was more likely to be So-eumin than So-yangin (Table 3).

The genotypes of G2677T/A SNP are more diverse because guanine can be changed to either thymine or adenine. In particular, the frequency of $\mathrm{G} / \mathrm{A}$ type changing to adenine was $3 \%$ in Caucasians, $6 \%$ in Asians, almost $0 \%$ in blacks, but as high as around $20 \%$ in Japanese (28). Similar to the report showing that the distribution of G2677T/A was not very different between Koreans and Japanese (4), the percentage of the G/A type was as high as over $16 \%$ in this study. In addition, when the distribution of the G2677T/A allele was compared with other races, the frequency of the A allele was high in Asians, but lower in Caucasians and Blacks $(27,29)$. The distribution of the G2677T/A genotype was not significantly different among the Sasang constitution, probably because there were as many as six genotypes. On the contrary, the distribution of the G2677T/A allele was significantly different among the Sasang constitutions (Table 4). In particular, Taeeumin showed a high frequency of the $\mathrm{G}$ allele, a wildtype, and low frequency of $\mathrm{T}$ and $\mathrm{A}$ allele, which are mutant types. Thus Tae-eumin was significantly different from So-yangin, which showed a higher frequency of the $\mathrm{T}$ and $\mathrm{A}$ alleles. This result was not significant with regards to the genotype, but the frequency of the homozygous $\mathrm{G} / \mathrm{G}$ type was almost two times higher in Tae-eumin than in So-yangin or So-eumin.

C3435T polymorphism is known to change the expression of P-gp and its ability to transport drugs (30). The activity of $\mathrm{P}$-gp is highest in the homozygous $\mathrm{C} / \mathrm{C}$ type, moderate in the heterozygous $\mathrm{C} / \mathrm{T}$ type, and lowest in the homozygous $\mathrm{T} / \mathrm{T}$ type (31). It was reported that the homozygous $\mathrm{T} / \mathrm{T}$ type showed a lower expression of $\mathrm{P}$-gp and as a result, patients of this type showed a high blood digoxin level after oral administration of digoxin (32). The distribution pattern of C3435T reported in the present study was also similar to another report showing that the distribution of C3435T in Koreans was different from that of Caucasian and Blacks and similar to that of the Japanese (33). The distribution of the C3435T genotype was not significantly different among the Sasang constitutions. Moreover, the distribution of alleles did not show any significant difference among the Sasang constitutions. However, the frequency of the homozygous $\mathrm{C} / \mathrm{C}$ type was higher in Tae-eumin than in So-eumin or So-yangin.

When three SNPs were examined at the same time, a total of 11 MDRl gene haplotypes were identified. The results of the percentage of haplotypes was supported by another report demonstrating that the percentage in Koreans was different from that of Caucasians and similar to that of Chinese (Table 6) $(18,26,33)$.

Table 6. Frequencies of MDR1 haplotypes in Korean compared with other populations

\begin{tabular}{llllll}
\hline \multicolumn{2}{l}{ Haplotypes of MDR1 } & gene & $\begin{array}{l}\text { German } \\
\text { Caucasian } \%\end{array}$ & $\begin{array}{l}\text { Chinese } \\
\text { Han } \% \\
(n=165)\end{array}$ & Korean $\%$ \\
\cline { 1 - 4 } T1236C & G2677T/A & C3435T & $(n=461)$ & $(n=7)$ \\
\hline $\mathrm{T}$ & $\mathrm{T}$ & $\mathrm{T}$ & 41.0 & 33.3 & 26.5 \\
$\mathrm{C}$ & $\mathrm{G}$ & $\mathrm{C}$ & 37.0 & 20.1 & 20.4 \\
$\mathrm{~T}$ & $\mathrm{G}$ & $\mathrm{C}$ & 1.0 & 22.2 & 18.6 \\
$\mathrm{C}$ & $\mathrm{A}$ & $\mathrm{C}$ & 2.5 & 11.3 & 14.5 \\
$\mathrm{~T}$ & $\mathrm{~T}$ & $\mathrm{C}$ & 2.5 & 5.6 & 5.2 \\
$\mathrm{~T}$ & $\mathrm{G}$ & $\mathrm{T}$ & 0.5 & 1.0 & 3.9 \\
$\mathrm{C}$ & $\mathrm{T}$ & $\mathrm{C}$ & 1.5 & 1.7 & 3.4 \\
$\mathrm{~T}$ & $\mathrm{~A}$ & $\mathrm{C}$ & 0.0 & 1.2 & 2.9 \\
$\mathrm{C}$ & $\mathrm{T}$ & $\mathrm{T}$ & 1.0 & 1.6 & 1.7 \\
$\mathrm{~T}$ & $\mathrm{~A}$ & $\mathrm{~T}$ & 0.0 & 0.4 & 1.6 \\
$\mathrm{C}$ & $\mathrm{G}$ & $\mathrm{T}$ & 12.0 & 1.2 & 1.3 \\
$\mathrm{C}$ & $\mathrm{A}$ & $\mathrm{T}$ & 1.0 & 0.4 & 0.0 \\
Reference & & & 19 & 24 & This study \\
\hline
\end{tabular}


Particularly as in Sai et al., haplotype 1236T-2677T$3435 \mathrm{~T}$ showed the highest frequency in Japanese and Koreans. However, haplotype 1236T-2677T-3435T is quite rare in Blacks and haplotype 1236C-2677G-3435C is found in $43 \%$ of the Black population (34). It was reported that, in patients with haplotype 1236T-2677T$3435 \mathrm{~T}$, the metabolism of irinotecan, an anticancer drug, was relatively slow and as a result renal clearance was low (35). When digoxin was administered, haplotype $2677 \mathrm{G} / 3435 \mathrm{C}$ including the second most frequent 1236C-2677G-3435C and 1236T-2677G-3435C showed low digoxin concentration. On the contrary, haplotype $2677 \mathrm{G} / 3435 \mathrm{~T}$, which was observed rarely in this study, shows higher digoxin concentration (36).

The haplotype is not only dependent on racial characteristics but is also associated with the activity of the MDRl gene. The present study confirmed the existence of significant differences in the distribution of haplotypes between So-yangin and other constitutions. The frequency of the $1236 \mathrm{C}-2677 \mathrm{G}-3435 \mathrm{C}$ type, which is one of the major haplotypes, was lower in So-yangin than in Tae-eumin and So-eumin, and the difference was particularly significant between So-yangin and So-eumin. Furthermore, the frequency of the 1236T-2677G-3435T type was significantly lower in So-eumin than in So-yangin. Besides, haplotypes 1236T-2677A-3435C and 1236C-2677T-3435T showed a significant difference between So-yangin and other constitutions, but the frequency was too low (Table 5). In haplotype analysis, as the number of each group was small, the statistical significance was low. Thus, it is necessary to increase the number of subjects and confirm whether the frequency was actually high in So-yangin.

The results of the present study suggested that the polymorphism of the MDRl gene was not an indicator usable in diagnosis of all the constitutions but could be used to specifically distinguish So-yangin from the other constitutions. The MDRl C1236T genotype and haplotypes 1236C-2677G-3435C and 1236T-2677G-3435T might be considered beneficial indicators to distinguish between So-yangin and So-eumin among the Sasang constitutions. The MDR1 G2677T/A gene allele could be used to distinguish between So-yangin and Tae-eumin.

On the basis of the results of this study, we need to explore the metabolism of medicinal herbs used differently according to Sasang constitution. Recently, a study was conducted on the relationship between the MDRI genotype and the incidence of femoral head necrosis as a serious side effect of steroids, which are used as immunosuppressive agents in preventing transplantation rejection in patients who had renal transplantation. Patients with 3435T/T genotype showed high P-gp activity and consequently, low incidence of femoral head necrosis (37). In addition, there was a report showing that because the MDRI 2677 homozygous variant type showed a low incidence of femoral head necrosis, examination of C3435T and G2677T/A polymorphism before the administration of steroids might be beneficial in predicting the incidence of femoral head necrosis as a side effect of the medication. It is considered necessary to determine the association between the metabolism of medicinal herbs and MDRI by applying these methodologies to Sasang medicine, and to increase the sample size and determine whether there are any differences in reaction to or concentration of the drug metabolized by MDRI based on the constitution of the individual.

The present study examined the association between C1236T, G2677T/A and C3435T among MDR1 gene polymorphisms and Sasang constitutions with 207 subjects who were in their 20-30s and whose Sasang constitutions were diagnosed. There were statistically significant differences in the distribution of the MDR1 C1236T genotype between So-yangin and So-eumin. Also, the distribution of the MDR1 G2677T/A allele was significantly different between So-yangin and Taeeumin. Furthermore, there was a significant difference in the distribution of $1236 \mathrm{C}-2677 \mathrm{G}-3435 \mathrm{C}$, which is a major haplotype of $M D R 1$, as well as $1236 \mathrm{~T}-2677 \mathrm{G}-$ 3435T between So-yangin and So-eumin.

\section{Perspectives}

Although diagnosis of Sasang constitutions is very critical for SCM disease treatment, many of them fail to achieve accordance of diagnosis. The diagnosis need many characteristics of the patient, but surely the final decision is made by the drug response. For consistent diagnosis, we are required to know or expect the response to the main drugs in SCM.

These results suggest that polymorphisms of the gene MDRl affecting drug transporters in the body can be evidence that constitutional differentiation may arise due to genetic differences. It showed a different distribution between the three constitution types and can be considered to have some diagnostic value in constitutional typing. Furthermore, it is necessary to investigate the association between the metabolism of medicinal herbs and the MDRl gene, and to increase the sample size and determine whether there are any differences in reaction to or concentration of drug metabolized by $M D R 1$ according to constitution of the individual.

\section{Funding}

Korea Science and Engineering Foundation (KOSEF) grant funded by the Korea Government (MEST) (No. M10643020001-08N4302-00100) and Wonkwang University in 2008. 


\section{References}

1. Chae H, Lyoo IK, Lee SJ, Cho S, Bae H, Hong M, et al An alternative way to individualized medicine: psychological and physical traits of sasang typology. J Alternative Complement Med 2003;9:519-28.

2. Jang E-S, Kim H-S, Lee H-J, Baek Y-H, Lee S-W. The clinical study on the ordinary and pathological symptoms according to Sasang constitution. J Sasang Constitutional Medicine 2007;19: $144-55$.

3. Lee JM, Choi SH. Longevity \& Life Preservation in Oriental Medicine. Seoul: Kyung Hee University Press, 1996.

4. Kim D-Y, Lee J-W, Kim D-R. Statistical study on heredity in Sasang constitutional medicine. J Sasang Constitutional Med 1999;11:159-68.

5. Choi SH, Yim YB, Rhee JW, Kim HY, Kang CH. Relationship between the Sasang constitution and ACE polymorphism. J Sasang Constitutional Med 1998;10:283-90.

6. Ha M-S, Koh B-H, Song I-B. A study on the correlation between Sasang constitution and HLA type. J Sasang Constitutional Med 2002;14:90-9.

7. Moon SW, Park JH, Yeom SR, Lee SK, Shin BC, Kwon YD, et al. Study on relationship among interleukin-1 receptor antagonist gene polymorphism, obesity and Sasang constitution in Korean women. J Orient Rehab Med 2004;14:23-35.

8. Lee J-H, Seo B-Y, Han S-Y, Yeom SR, Lee SK, Kwon YD, et al. Study on relationship between interleukin-1 beta gene polymorphism and Sasang constitution in Korean obese women. $J$ Orient Rehab Med 2005;15:127-37.

9. Lee S-K, Lee S-G. Genetic polymorphism of CCK promotor region and Sasang constitution. J Korean Orient Med 2004;25:105-10.

10. Lee S-G, Kim H-J, Park H-J, Lee J-H, Kwon D-G, Joo J-C, et al. Association between genetic polymorphism of the cytochrome P450 2C19, 2D6 and types of Sasang constitutional medicine. J Korean Orient Med 2007;28:51-62.

11. Park JO, Lim NK, Lee YH, Chae HJ, Namgung U, Kim DH. Studies on the SNPs and haplotype of cytochrome P450 gene in Tae-eum, So-yang and So-eum persons. Korean J Orient Physiol Pathol 2002;16:1201-6.

12. Chavan P, Joshi K, Patwardhan B. DNA microarrays in herbal drug research. eCAM 2006;3:447-57.

13. Juliano RL, Ling V. A surface glycoprotein modulating drug permeability in Chinease hamster ovary cell mutants. Biochim Biophys Acta 1976;455:15262.

14. Thiebaut F, Tsuruo T, Hamada H, Gottesman MM, Pastan I, Willingham MC. Cellular localization of the multidrug-resistance gene product P-glycoprotein in normal human tissues. Proc Natl Acad Sci USA 1987;84:7735-8.

15. Cordon-Cardo C, O'Brien JP, Casals D, Rittman-Grauer L, Biedler JL, Melamed MR, et al. Multidrug-resistance gene (P-glycoprotein) is expressed by endothelial cells at bood-brain barrier sites. Proc Natl Acad Sci USA 1989;86:695-8.

16. Greiner B, Eichelbaum M, Fritz P, Kreichgauer HP, Von Richer O, Zundler J. The role of intestinal P-glycoprotein in the interaction of digoxin and rifampin. J Clin Invest 1999;104:147-53.

17. Schwab M, Eichelbaum M, Fromm MF. Genetic polymorphisms of the human MDR1 drug transporter. Annu Rev Pharmacol Toxicol 2003;58:809-12.

18. Cascorbi I, Gerloff T, Johne A, Meisel C, Hoffmeyer S, Schwab M, et al. Frequency of single nucleotide polymorphisms in the P-glycoprotein drug transporter MDR1 gene in white subjects. Clin Pharmacol Ther 2001;69:169-74.

19. Meisel C, Roots I, Cascorbi I, Brinkmann U, Brockmoller J. How to manage individualized drug therapy: application of pharmacogenetic knowledge of drug metabolism and transport. Clin Chem Lab Med 2000;38:869-76.
20. Lee JM. Dong-Yi-Soo-Se-Bo-Won. Seoul, Korea: Je Ma Lee, 1894 (in Korean).

21. Kim SH, Koh BH, Song IB. A study on the standardization of QSCC $\alpha$. J Sasang Constitutional Med 1995;7:187-246.

22. Lee SW, Joo JC, Lee SK, Lee HJ, Jang ES. A study on the response differences to the sasang constitution questionnaire by sasang constitutions. J Sasang Constitutional Med 2007;19:89-98.

23. Excoffier L, Slatkin M. Maximum-likelihood estimation of molecular haplotype frequencies in a diploid population. Mol Biol Evol 1995;12:921-7.

24. Drysdale CM, McGraw DW, Stack CB, Stephens JC, Judson RS, Nandabalan K, et al. Complex promoter and coding region beta 2-adrenergic receptor haplotypes alter receptor expression and predict in vivo responsiveness. Proc Natl Acad Sci USA 2000; 97:10483-8.

25. Ryu HC, Kwon HY, Choi IK, Rhee DK. Analyses of single nucleotide polymorphisms and haplotype linkage of the human ABCB1 (MDR1) gene in Korean. Arch Pharm Res 2006;29:1132-9.

26. Li D, Zhang GL, Lou YQ, Li Q, Wang X, Bu XY. Genetic polymorphisms in MDR1 and CYP3A5 and MDR1 haplotype in mainland Chinese Han, Uygur and Kazakh ethnic groups. J Clin Pharm Ther 2007;32:89-95.

27. Komoto C, Nakamura T, Sakaeda T, Kroetz DL, Yamada T, Omatsu H, et al. MDR1 haplotype frequencies in Japanese and Caucasian, and in Japanese patients with colorectal cancer and esophageal cancer. Drug Metab Pharmacokin 2006;21:126-32.

28. Ozawa S, Soyama A, Saeki M, Fukushima-Uesaka H, Itoda M, Koyano S, et al. Ethnic differences in genetic polymorphisms of CYP2D6, CYP2C19, CYP3As and MDR1/ABCB1. Drug Metab Pharmacokin 2004;19:83-95.

29. Kroetz DL, Pauli-Magnus C, Hodges LM, Huang CC, Kawamoto M, Johns SJ, et al. Sequence diversity and haplotype structure in the human ABCB1 (MDR1, multidrug resistance transporter) gene. Pharmacogenetics 2003;13:481-94.

30. Goto M, Masuda S, Saito H, Uemoto S, Kiuchi T, Tanaka K. C3435T polymorphism in the MDR1 gene affects the enterocyte expression level of CYP3A4 rather than Pgp in recipients livingdonor liver transplantation. Pharmacogenetics 2002;12:451-7.

31. Jamroziak K, Balcerczak E, Smolewski P, Robey RW, Cebula B, Panczyk M, et al. MDR1(ABCB1) gene polymorphism C3435T is associated with P-glycoprotein activity in B-cell chronic lymphocytic leukemia. Pharmacol Rep 2006;58:720-8.

32. Hoffmeyer S, Burk O, von Richter O, Arnold HP, Brockmöller J, Johne A, et al. Functional polymorphisms of the human multidrugresistance gene: multiple sequence variations and correlation of one allele with P-glycoprotein expression and activity in vivo. Proc Natl Acad Sci USA 2000;97:3473-8.

33. Kim YO, Kim MK, Woo YJ, Lee MC, Kim JH, Park KW, et al. Single nucleotide polymorphisms in the multidrug resistance 1 gene in Korean epileptics. Seizure 2006;15:67-72.

34. Sai K, Kaniwa N, Itoda M, Saito Y, Hasegawa R, Komamura K, et al. Haplotype analysis of ABCB1/MDR1 blocks in a Japanese population reveals genotype-dependent renal clearance of irinotecan. Pharmacogenetics 2003;13:741-57.

35. Marzolini C, Paus E, Buclin T, Kim RB. Polymorphisms in human MDR1 (P-glycoprotein): recent advances and clinical relevance. Clin Pharmacol Ther 2004;75:13-33.

36. Johne A, Köpke K, Gerloff T, Mai I, Rietbrock S, Meisel C, et al. Modulation of steady-state kinetics of digoxin by haplotypes of the P-glycoprotein MDR1 gene. Clin Pharmacol Ther 2002;72:584-94.

37. Asano $T$, Takahashi KA, Fujioka M, Inoue S, Okamoto M, Sugioka N, et al. ABCB1 C3435T and G2677T/A polymorphism decreased the risk for steroid-induced osteonecrosis of the femoral head after kidney transplantation. Pharmacogenetics 2003;13: $675-82$.

Received March 16, 2009; accepted July 31, 2009 


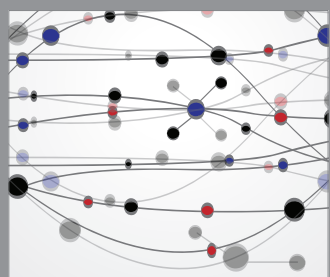

The Scientific World Journal
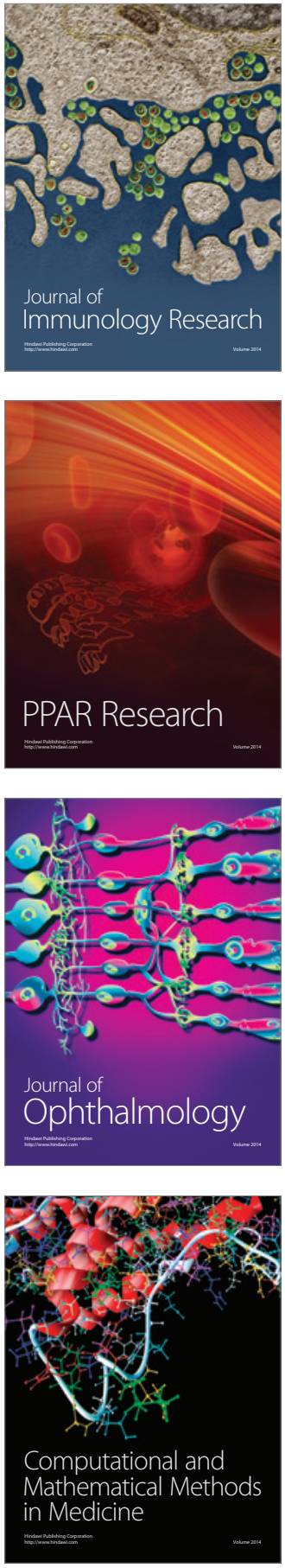

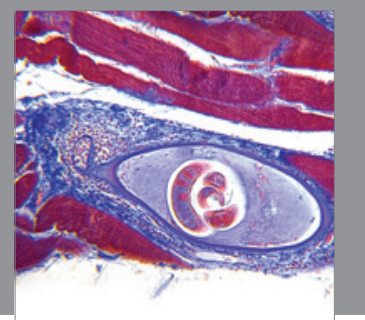

Gastroenterology

Research and Practice
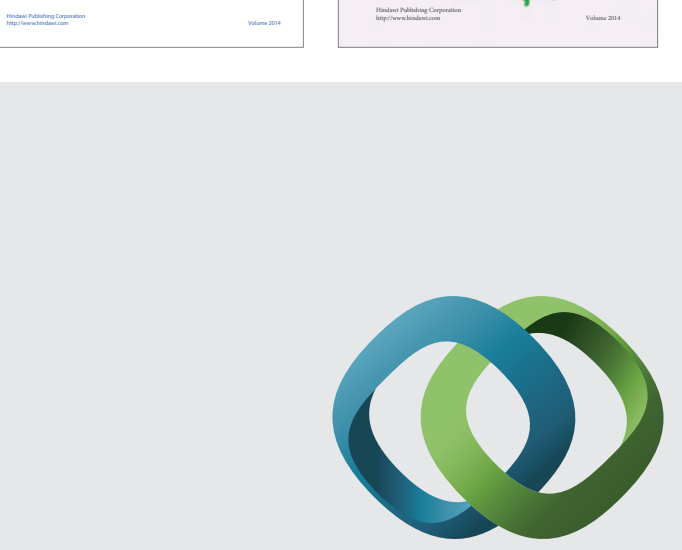

\section{Hindawi}

Submit your manuscripts at

http://www.hindawi.com
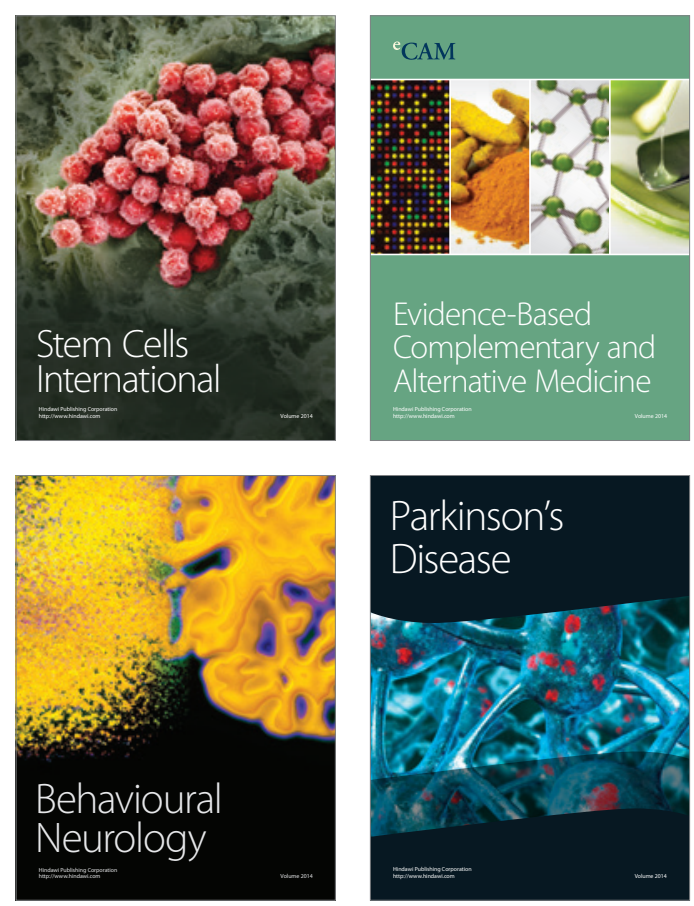

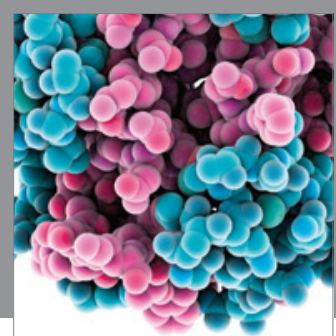

Journal of
Diabetes Research

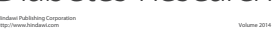

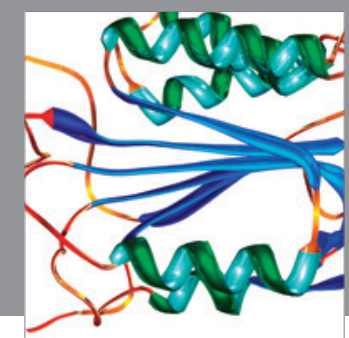

Disease Markers
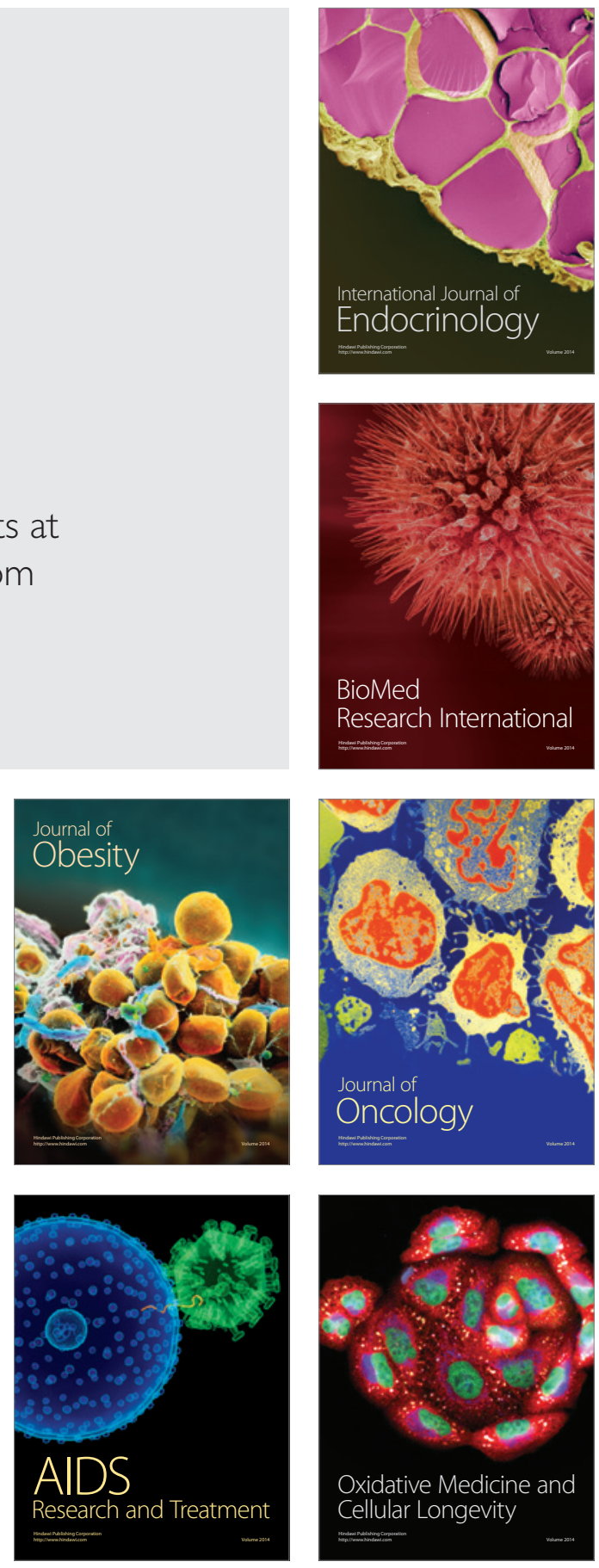